\title{
LEX MERCATORIA: ¿ORDEN JURÍDICO AUTÓNOMO?
}

\section{LEX MERCATORIA: ORDEM JURÍDICA AUTONOMA?}

Frederico E. Z. Glitz $z^{*}$

Resumen: La noción de lo que sería la Lex mercatoria debe someterse a una reevaluación. En cierto sentido, los fenómenos globalizadores contemporáneos propagaran la idea de que habría un conjunto autónomo de reglas que gobernaría las actividades comerciales transnacionales, liberándolos de las barreras de derecho interno. Este artículo tiene como objetivo analizar las consecuencias normativas de la aceptación de la existencia de un sistema legal independiente. A partir de una revisión de la literatura, el artículo concluye que, aunque se pueda cuestionar el alcance de la autonomía de la lex mercatoria, deben reconocer la importancia de las fuentes normativas que la componen.

Resumo: A noção do que venha a ser a Lex mercatoria precisa passar por reavaliação. Em algum sentido os fenômenos globalizantes contemporâneos acabaram difundindo a ideia de que existiria um conjunto normativo próprio a reger as atividades empresariais transnacionais, libertando-as dos entraves do Direito nacional. O presente artigo teve por objetivo a análise das consequências normativas da aceitação da existência desta eventual ordem jurídica autônoma. A partir de uma pesquisa bibliográfica, o artigo conclui que ainda que se possa questionar a amplitude da autonomia da lex mercatoria, deve-se reconhecer a relevância normativa das fontes que a compõem.

Palabras clave: Lex mercatoria, Orden jurídico, Autonomía Palavras-chave: Lex mercatória, Ordem jurídica, Autonomia

\section{INTRODUCCIÓN}

En lo que concierne al Derecho comercial internacional es común que se reconozca a la costumbre como una de sus fuentes de

* Centro Universitario de Curitiba, Brasil. Universidad Comunitaria de Chapecó (UNOCHAPECO), Brasil.

E-mail: Frederico@fredericoglitz.adv.br

Recibido: 26/10/2016. Aceptado: 15/03/2017. 
obligaciones contractuales. Esta comprensión está tan diseminada que actualmente se encuentran fundamentos para justificar la existencia de un sistema normativo autónomo e independiente de la soberanía estatal. Tal autonomía habría sido alcanzada en base a cierta uniformidad de las fuentes normativas, especialmente basada en prácticas comerciales, cláusulas contractuales padrón (contratos tipo), regulaciones corporativas, jurisprudencia arbitral y tentativas de armonización del Derecho comercial internacional (Principios UNIDROIT, Reglamentos UNCITRAL, ICSID o de la OMPI $)^{1}$.

La importancia de esa discusión reside justamente en el papel que desempeña la costumbre como fuente de obligaciones contractuales dentro de una lógica normativa no estrictamente relacionada al paradigma estatal. Se trata de una oportunidad de entender cómo en un ordenamiento pluralista, diversas fuentes de obligaciones pueden convivir sin que precisen ser necesariamente explicadas a partir de un origen común.

Por otro lado, la comprensión de los mecanismos típicos de la llamada Lex mercatoria ayuda a comprender los límites que enfrenta la explicación horizontal de ordenamiento. En otros términos, de alguna forma, la unidad sistematizada necesita ser alcanzada. Se debe tener en mente aún la advertencia de que la unificación de un Derecho comercial transnacional trae igualmente el riesgo de la extinción de la diversidad normativa ${ }^{2}$.

Estas preocupaciones quedan bien en claro si se acepta la explicación de Grossi de que la Lex marcatoria sería un fenómeno cargado de luces y sombras, es decir, portador al mismo tiempo de valores positivos (ya que consagra la noción pluralista de normatividad) y negativos (pues carga con la pretensión económica de apoderarse de un Derecho instrumento de sus fines) ${ }^{3}$. Oppetit deja aún más en claro la importancia metodológica de comprensión del fenómeno, especialmente porque, en su opinión, hay una verdadera revitalización de la discusión en torno de las fuentes normativas.

Al supuesto espacio de libertad de creación normativa, se le ha dado el nombre de nueva lex mercatoria, la cual puede ser entendida de

1 CARDENA AFANADOR, Walter René. "La nueva lex mercatoria: un caso pionero en la globalización del derecho". Papel Político. 2001, n 13, out. p. 110-111.

2 PROCACCIA, Uriel. "The case Against Lex Mercatoria”. In: ZIEGEL, Jacob S. (ed.). New Developments in International Commercial and Consumer Law: proceedings of the 8th Biennial Conference of the International Academy of Commercial and Consumer Law. Oxford: Hart, 1998, p. 89.

3 GROSSI, Paolo. De la codificación a la globalización del derecho. Pamplona: Aranzadi, 2010, p. 357.

4 "Desde ya el desconforto de esta situación deja dos opciones: o la resignación al positivismo legalista reductor, que mantiene la dogmática clásica de las fuentes del derecho al mismo tiempo en que descalifica una parte del fenómeno jurídico, o la aceptación de la perspectiva pluralista al precio del abandono de una teoría ligada a cierta forma de comprender el Estado y el Derecho". OPPETIT, Bruno. Droit et modernité. París: Puf, 1998, p. 58. 
dos formas: adjetiva o procedimental y sustancial o material ${ }^{5}$. En otros términos, se puede indagar acerca de cuál es el papel de sus diferentes normativas y cómo se relacionan entre sí y con las fuentes típicamente estatales.

El debate que se propone en este artículo es si el contenido de la lex mercatoria podría ser considerado jurídico y, si así lo fuese, si podría ser considerado un nuevo orden jurídico y, si así también lo fuese, si ésta sería autónoma en relación al Derecho estatal.

\section{LEX MERCATORIA: ¿ORDEN JURÍDICO AUTÓNOMO?}

Para el desarrollo de una respuesta inicial a las cuestiones indicadas anteriormente, es necesario se destacar dos posicionamientos doctrinarios: (i) aquellos vinculados a la concepción de que cualquier orden jurídico necesariamente emana de una autoridad legalmente establecida, provista de soberanía y poder de imposición de sus decisiones ${ }^{6}$ y (ii) aquellos que vislumbraban la posibilidad de creación normativa autónoma del concepto de soberanía y de autoridad estatal.

Dentro de la doctrina jurídica tradicional, esta comprensión podría ser resumida en las corrientes descriptas como monistas y pluralistas, y que debatían sobre el papel del Estado frente a la producción normativa internacional.

La novedad en el discurso de los defensores de la nueva Lex mercatoria no está apenas en la concepción de que habría un orden jurídico internacional que influiría en el poder normativo del Estado sino en que este orden jurídico podría ser autónomo a él y no depender de su consentimiento para existir ni situarse en los niveles tradicionales del diálogo de soberanía compartido entre los demás Estados.

Goldman, pionero en la discusión, explicaba que la incertidumbre en relación a las reglas de conflicto o a la aplicación judicial de ellas ya serían suficientes para explicar la fuga de los contratantes en relación al Derecho estatal. Mientras tanto, durante el siglo XIX varias iniciativas de uniformización de condiciones comerciales (contratos-tipo) fueron exitosas para proveer un cuadro general interpretativo y de regencia de aquellas relaciones. En el mismo sentido, se habrían desarrollado las reglas sobre las operaciones de crédito, transporte y estatutos de sociedades internacionales ${ }^{7}$.

5 NOTTAGE, Luke. "Changing Contract Lenses: unexpected supervening events in English, New Zeland, U. S. and Japanese, and International Sales Law and Practice". Indiana Journal of Global Legal Studies. 2007, vol 14, n² 2, p. 386.

6 Por ejemplo: SCHULTZ, Thomas. "The concept of law in transnational arbitral legal orders and some of its consequences". Journal of International Dispute Settlement. 2011, vol 2, n' 1 , p. $59-85$.

7 GOLDMAN, Berthold. "Frontières du Droit et Lex mercatoria". Archives de Philosophie du Droit. 1964, vol 9, n 9, p. 177-183. 
Incluso según Goldman, cuando fueron instadas a resolver eventuales conflictos oriundos del comercio internacional, las Cortes arbitrales recurrieron a las reglas costumbristas relacionadas a aquella actividad, en detrimento de un reglamento nacional cualquiera, normalmente insuficiente para la solución de dicha lid ${ }^{8}$.

En síntesis, según Feldstein, la inadecuación de los Derechos nacionales, la actuación arbitral como jurisdicción independiente, los procedimientos de amiable compusiteur y la formación de jurisprudencia arbitral terminarían favoreciendo la formación de la Lex mercatoria ${ }^{9}$.

Goldman también refuta la naturaleza contractual de la Lex mercatoria, esto es, niega que su fundamento sea la libertad contractual individual, sino que es la sumisión a la reglas "generales y abstractas"10. Aunque Goldman, en un segundo momento, reconoce que la lex mercatoria no sería un sistema jurídico completo ${ }^{11}$, entendía que sus normas tendrían carácter jurídico ya que tendrían carácter general, proveniente de una autoridad (aunque no estatal) y estarían provistas de sanción (aunque ocasionalmente proporcionadas por el Estado) ${ }^{12}$.

Lagarde, por su lado, guardaba una postura más crítica en relación a la tesis de Goldman, especialmente afirmando que no todas las reglas identificadas por éste como lex mercatoria estarían en condiciones de ser consideradas como orden jurídico estatal pero sí como simple "práctica contractual internacional"13. En otros términos, estaría formada por un todo "inorgánico" y "fragmentado"14 que no tendría condiciones sistemáticas.

Además, según Lagarde, explicar la Lex mercatoria por el conjunto de reglas que la constituyen haría depender cualquier consecuencia del préstamo de principios generales del Derecho internacional ${ }^{15}$. En este mismo sentido, parece apuntar Gaillard, para quien los principios generales del Derecho comercial internacional deben entenderse como reglas no vinculadas a un solo sistema jurídico, pero que se desprenden de la comparación de los diferentes Derechos nacionales o directamente de sus fuentes ${ }^{16}$. De esa forma, serían distintos de los usos comerciales

8 Íbidem., p. 183-184.

9 FELDSTEIN DE CÁRDENAS, Sara. Contratos internacionales. Contratos celebrados por ordenador: Autonomía de la voluntad: Lex mercatoria. Buenos Aires: Abeledo-Perrot, 1995, p. 166.

10 GOLDMAN, Berthold. Op. cit., p. 180-181.

11 GOLDMAN, Berthold. "Nouvelles Réflexions sur la Lex Mercatoria". Festschrift Pierre Lalive. Franckfurt: sn., 1993, p. 241-255.

12 GOLDMAN, Berthold. Frontieres du Droit..., p. 188-192.

13 LAGARDE, Paul. "Approche critique de la Lex mercatoria”. In FOUCHARD, Philippe et al. (eds.). Le droit des relations économiques internationals: etudes offertes a Berthold Goldman. París. Librairies Techniques, 1982, p. 130.

14 GONDRA ROMERO, Jose Maria. “La moderna 'lex mercatoria’ y la unificación del derecho del comercio internacional”. Revista de Derecho Mercantil. 1973, n 127, p. 23.

15 LAGARDE, Paul. Op. cit., p. 133.

16 GAILLARD, Emmanuel. "La distinction des principles généraux du Droit et des usages du commerce international”. In Etudes offertes a Pierre Bellet. París: Litec, 1991, p. 204. 
internacionales que se ligarían a las prácticas habitualmente seguidas por un determinado ramo comercial o, más genéricamente, desvinculadas de otras fuentes normativas ${ }^{17}$. También Kassis se alinea a esta explicación dejando en claro que la llamada lex mercatoria no tendría naturaleza de norma consuetudinaria, por lo tanto no tendría aplicación cogente, y que existirían, en términos comerciales internacionales, apenas los usos convencionales dependientes de la convención. El autor destacaba, entonces, que no se podría aceptar la idea de un Derecho no nacional, transnacional o de la lex mercatoria entendida como tal ${ }^{18}$.

Lagarde tampoco concuerda con la afirmación de la generalidad que haría presuponer la existencia de un orden jurídico autónomo, pero sí de "islas de la lex mercatoria" dada la verificación puntual de sumisión a ella ${ }^{19}$. Incluso cuando se propone explicar el contrato internacional, defiende abiertamente que la libertad contractual es la condición necesaria (aunque no suficiente) para su regencia por la Lex mercatoria. En relación al arbitraje, o bien en cuanto a la cláusula o bien en cuanto a la posibilidad de juzgamiento por otras reglas de Derecho y principios generales del comercio, también es indispensable el consenso ${ }^{20}$. Para Lagarde, la argumentación de defensa de la Lex mercatoria alejaría la posibilidad de su coexistencia con el orden jurídico estatal.

La propia idea de autonomía jurisdiccional podría quedar comprometida si se tiene en cuenta la necesidad de apoyo estatal para la ejecución de laudos arbitrales extranjeros ${ }^{21}$. En otros términos, no habría exclusividad jurisdiccional ya que no se podría sustraer completamente la competencia del Derecho nacional ${ }^{22}$. Este posicionamiento se aproximaba más a aquellos defendidos por Schmitthoff de que la Lex mercatoria estaría condicionada a los límites del orden público y se fundaría en el conocimiento, directo o indirecto, del Estado que de alguna forma toleraría su existencia ${ }^{23}$.

Según López Rodríguez, esta división entre la corriente autonomista y la corriente positivista no reflejaría adecuadamente el fenómeno porque si de un lado la lex mercatoria no podría existir independientemente del Estado, por el otro, algunas de sus fuentes tienen existencia independiente de la aprobación estatal ${ }^{24}$. Coherente

17 Ibíd., p. 206-207.

18 KASSIS, Antoine. Théorie générale des usages du commerce: droit compare, contrats et arbitrage internationaux, lex mercatoria. Paris: LGDJ, 1984, passim. Especialmente las conclusiones de las páginas 577-578.

19 LAGARDE, Paul. Op. cit., p. 140.

20 Ibíd, p. 140-145.

21 GONDRA ROMERO, José Maria. Op. cit., p. 24.

22 BRITO, Maria Helena. Direito do comércio internacional. Coimbra: Almedina, 2004, p. 123. 23 SCHMITTHOFF, Clive M. "Les nouvelles sources du Droit commercial international. UNESCO”. Revue Internationale des sciences socials. 1963, vol 15, n² 2, p. 272.

24 LÓPEZ RODRÍGUEZ, Ana M. Lex mercatoria and harmonization of contract law in the EU. Copenhagen: DJOF Publishing, 2003, p. 92. 
con este razonamiento, Molineaux argumenta - a partir de los laudos arbitrales en el sector de la construcción civil - que la lex mercatoria sería complementaria del Derecho aplicable al contrato ${ }^{25}$.

En esa misma línea, se manifiesta Goode para quien "ningún contrato puede referirse a su propia validez y ningún sistema permite la libertad absoluta a las partes contratantes, cuyo acuerdo se ve en todas partes limitado por reglas de orden público y las normas imperativas"26.

La doctrina más contemporánea crea incluso una cuarta variable teórica: la posibilidad de convivencia de los dos órdenes a depender de la jurisdicción ${ }^{27}$. Así, habría prevalencia del orden jurídico interno si la jurisdicción estatal es llamada a manifestarse acerca del conflicto. Por otro lado, habría prevalencia de la Lex mercatoria si la jurisdicción arbitral fuese invocada ${ }^{28}$, manteniendo entre sí un régimen de repartición de competencia, reciprocidad y cooperación ${ }^{29}$. De cualquier forma conviene destacar que la lex mercatoria no se confundiría con la existencia de un eventual ordenamiento jurídico arbitral. ${ }^{30}$

En cierto sentido, se identifica una tentativa de codificación del fenómeno con la finalidad de garantizar la aplicación generalizada de un "Derecho" adecuado a las relaciones comerciales internacionales, reduciéndose los costos en investigaciones y negociaciones, y evitándose los peligros de la asimetría de informaciones ${ }^{31}$. Aunque pudiese ser considerado paradojal, según Rosen, la codificación no sería inconsistente con la adopción de una solución independiente de las reglas de conflicto de leyes (Derecho internacional privado, basadas en Derecho nacional) y en la autonomía privada (no siempre reconocida) aunque ese trabajo no fuese ni espontáneo (como se espera de un Derecho costumbrista) ni anónimo (pero sí creado por juristas) ${ }^{32}$.

25 MOLINEAUX, Charles. “Moving Toward a Lex Mercatoria - A lex Constructionis". J. Int'l Arb. 1997, vol 14, no 1, p. 56.

26 GOODE, Roy. "Regla, práctica y pragmatismo en el derecho comercial transnacional". In: BW, Jürgen; FERNÁNDEZ ARROYO, Diego P.; MORENO RODRIGUEZ, José A. (eds.). Cómo se codifica hoy el derecho comercial internacional. Asunción: La Ley/CEDEP, 2010, p. 87. 27 FERNÁNDEZ ROZAS, José Carlos. "Lex mercatoria y autonomía conflictual en la contratación internacional". In: Anuario Español de Derecho Internacional Privado. Madrid: Iprolex, 2004, tomo 4, p. 40.

28 PINHEIRO, Luis de Lima. Direito Internacional Privado: introdução e direito de conflitos. Parte geral. 2 ed. Coimbra: Almedina, 2008, v. 1, p. 118.

29 OSMAN, Filali. Les príncipes généraux de la lex mercatoria: contribution a l'etude d'un ordre juridique anational. París: LGDJ, 1992, p. 456.

30 Según Gaillard, mientras que la discusión sobre la existencia de un Derecho arbitral se presentaría en la medida en que normas arbitrales serían aceptadas genéricamente por la comunidad internacional, la Lex mercatoria podría referirse al eventual Derecho aplicable a la cuestión de fondo de la disputa sometida al procedimiento arbitral. GAILLARD, Emmanuel. Teoría jurídica del arbitraje internacional. Asunción. La ley/CEDEP, 2010, p. 44-46.

31 ROSEN, Mark D. "The empirical and theoretical underpinnings of the Law Merchant: do codification and private international Law leave room for a new Law Merchant?". Chicago journal of International Law. 2004, vol 5, n 1, p. 86-87.

32 Idíd., p. 89. 
Según Pinheiro, sería la fase adulta - aún no alcanzada- de la Lex mercatoria en la que se afirmaría como un Derecho transnacional apto para regular los contratos internacionales del comercio $^{33}$; aunque dependiese del reconocimiento - inclusive indirecto del Estado - no formaría un ordenamiento autónomo ${ }^{34}$. Esta opinión es compartida por Oppetit, que entendía que la lex mercatoria no podría ser considerada un sistema jurídico completo pero sí en construcción ${ }^{35}$; Goode ${ }^{36}$, De $\mathrm{Ly}^{37}$ y otros ${ }^{38}$ consideran que una vez que la legislación nacional y las convenciones internacionales marcan su alcance, carecería de normas propias, no serviría de fundamento de validez de un laudo arbitral, no poseería marco interpretativo y regulador y no sería autosuficiente ${ }^{39}$. De esta forma, aunque se pueda admitir cierta autonomía práctica (además de efectiva y normativa) y pueda ser elegida como conjunto de reglas aplicable al contrato ${ }^{40}$, la lex mercatoria ${ }^{41}$ no sería absoluta ya que dependería del Estado para su vigencia y efectividad ${ }^{42}$. Su relación sería de complementariedad ${ }^{43}$.

Sin embargo, están aquellos que defienden su autonomía. Dalhuisen, por ejemplo, no sólo la entiende como sistema normativo completo, suplementado por el Derecho estatal, sino también como

33 PINHEIRO, Luís de Lima. Direito Internacional Privado: introdução e direito de conflitos. Parte geral. 2 ed. Coimbra: Almedina, 2008, vol 1, p. 127.

34 PINHEIRO, Luís de Lima. "O Direito autônomo do comércio internacional em transição: a adolescência de uma nova Lex mercatoria". In: Estudos de Direito Civil, Direito Comercial e Direito Comercial Internacional. Coimbra: Almedina, 2006, p. 427.

35 OPPETIT, Bruno. Droit et modernité. Paris: Puf, 1998, p. 61.

36 Aunque entienda que su elección como derecho aplicable puede ser efectiva, especialmente porque su normatividad estaría asegurada. GOODE, Roy. "Usage and its reception in transnational commercial Law”. In: International and Comparative Law Quarterly. 1997, vol 46, p. 33.

37 Habría incluso confusión entre la lex mercatoria autónoma y las fuentes del Derecho comercial internacional. DE LY, Filip. International business law and lex mercatoria. Amsterdam: North-Holland, 1992, p. 286-288.

38 GOODE, Roy; KRONKE, Herbert; MCKENDRICK, Ewan. Transnational commercial law: texts cases and materials. Oxford: Oxford press, 2007, p. 35; SARACHO CORNET, Teresita; DREYZIN DE KLOR, Adriana. Derecho internacional privado: una visión actualizada de las Fuentes. Córdoba: Advocatus, 2003, p. 58; CALVO CARAVACA, Alfonso-Luis. "Los contratos internacionales y el mito de la nueva lex mercatoria". In: Cadernos da Escola de Direito e Relações Internacionais da UniBrasil. 2010, $\mathrm{n}^{\circ}$ 12, p. 9-11; HOWARTH, Richard J. "Lex mercatoria: can general principles of law govern international commercial contracts?". Canterbury Law Review. 2004, vol 10, p. 75-76.

39 FELDSTEIN DE CÁRDENAS, Sara. Op. cit., p. 209-213.

40 GOODE, Roy. "Regla, práctica y pragmatismo en el derecho comercial transnacional". In: BASEDOW, Jürgen; FERNÁNDEZ ARROYO, Diego P.; Moreno Rodríguez, José A. (eds.). Cómo se codifica hoy el derecho comercial internacional. Asunción: La Ley/CEDEP, 2010, p. 93-94.

41 Ibíd., p. 89.

42 PINHEIRO, Luís de Lima. Op. cit., p. 43.

43 GOLDSTAJN, Aleksandar. "Usages of trade and other autonomous rules of international trade according to the UN (1980). Sales Convention". In: SARCEVIC, Petar; VOLKEN, Paul. (eds.). International Sale of Goods: Dubrovnik Lectures. New York: Oceana, 1986, p. 103. 
mandatorio en algunos $\operatorname{casos}^{44}$, prevaleciendo sobre disposiciones contractuales. En síntesis, según el autor, este sistema estaría formado por principios fundamentales con carácter de ius $\operatorname{cogens}^{45}$. En cambio, Pellet la compara, en términos de juridicidad, con el Derecho internacional público ${ }^{46}$, argumentando que sus fuentes serían suficientes para adoptarla de completud y autonomía de modo que se constituya en sistema "competente" al estatal ${ }^{47}$. Por último, se destaca la opinión de Berger que sostiene la existencia de un ordenamiento jurídico comercial autónomo y espontáneo, de carácter transnacional, que sacaría su "ímpetu" del Derecho internacional público, del Derecho comercial uniforme y del Derecho doméstico, sin compartir con ellos las características jurídicas ${ }^{48}$.

Posiciones intermedias son aquellas que: (i) entienden que aunque no pueda ser vista como un sistema jurídico autónomo del punto de vista positivista, tendría la capacidad de ser aplicada, por vía arbitral, como conjunto de "reglas de Derecho" y, por lo tanto, regir los contratos sometidos a ella $\mathrm{a}^{49}$; (ii) entienden que el régimen jurídico producto de la lex mercatoria sería híbrido, no existiendo tal dicotomía entre fuentes estatales y no estatales, motivo por el cual sería necesario el control y complemento de su contenido $0^{50}$ y (iii) negando el carácter sistemático de la lex mercatoria y sin entrar en la discusión sobre constituirse o no como método de formulación normativa, acaban reconociendo en el debate sobre la lex mercatoria su importancia metodológica como "transnational (prívate) law laboratory" 51 . Su importancia residiría en

44 DALHUISEN, J. H. "Custom and its revival in transnational private la". Duke Journal of comparative and international Law. 2008, vol 18, p. 357. Para mayores detalles de la jerarquía de las Fuentes ver: DALHUISEN, J. H. Dalhuisen on transnational and comparative commercial, financial and trade law. $3^{\mathrm{a}}$ ed. Oxford: Hart, 2007, p. 213-216. En el mismo sentido de establecer jerarquía de fuentes ver: GOLDSTAJN, Aleksandar. Op. cit., p. 99.

45 DALHUISEN, J. H. Dalhuisen on transnational..., p. 218-219.

46 Aunque aparentemente Molineaux no comparta la amplitud del concepto, argumenta que negar la existencia de la lex mercatoria sería negar la existencia del propio Derecho internacional. Además, así como en el DIP están los tratados que preveen Tribunales y cómo ejecutar sus decisiones, la Convención de Nueva York estaría para hacer lo mismo por la lex mercatoria. MOLINEAUX, Charles. "Moving toward a Lex Mercatoria - A Lex constructionis". J. Int'l Arb. 1997, vol 14, no 1, p. 66.

47 PELLET, Alain. "La lex mercatoria, 'Tiers Ordre Juridique'?". In: LEBEN, Charles, LOQUIN, Eric; SALEM, Mahmoud (eds.). Remarques Ingenues d'un Internationaliste de Droit Public. Souveraineté étatique et marchés internationaux a la fin du 20éme siele-Mélanges en l'honneur de Philippe Kahn. París: Litec, 2000, p. 73-74.

48 BERGER, Klaus Peter. The creeping codification of the new Lex mercatoria. $2^{\text {a }}$ ed. New York: Wolters Kluwer, 2010, p. 146.

49 GOODE, Roy; KRONKE, Herbert; MCKENDRICK, Ewan. Op. cit., p. 35; MANIRUZZAMAN, Abul F. M. "The lex mercatoria and international contracts: a challenge for international commercial arbitration”. American Uniform and International Law Review. 1999, vol 14, p. 732-734.

50 MICHAELS, Ralf. “The true Lex mercatoria: Law Beyond State”. Indiana Journal of Global Legal Studie. 2007, vol 14, nº 2, p. 467-468.

51 Traduccion libre: "laboratorio de Derecho transnacional privado", CALLIESS, Gralf-Peter; ZUMBANSEN, Peer. Rough consensus and running code: a theory of transnational private law. 
la adopción del método comparado que habría tenido "una relación productiva con el derecho contractual nacional marcado por el continuo desarrollo de la legislación y jurisprudencia contractual"52 para comprender el fenómeno del Derecho no nacional ${ }^{53}$.

\section{CONSECUENCIAS NORMATIVAS DEL DEBATE}

A pesar de no haber rigidez ${ }^{54}$ en sus disposiciones, este "Derecho" surgido de las relaciones comerciales tendría carácter jurídico y sería obligatorio. Su base formal sería la norma costumbrista que posee la misma certeza, previsibilidad y efectividad de la regla positiva, incluso cuando es oriunda de asociaciones profesionales, por cuenta del consenso en su utilización (y de la consecuente legitimación) ${ }^{55}$. Generalmente, su aplicación está asociada al procedimiento arbitral. ${ }^{56}$

$\mathrm{Si}$, por un lado, su marca es una vuelta a la experiencia, disminuyendo las distancias entre los hechos y el Derecho (el hecho deja de depender de la investidura jurídica ${ }^{57}$ ), por el otro, se percibe que es en la ausencia de limitaciones territoriales que se fortalece y en la efectividad que convence ${ }^{58}$.

El principal papel a desempeñar por la figura, en tiempos contemporáneos, sería el de solucionar de forma práctica "los conflictos que surgen en el comercio internacional, como una toma de conciencia de las legislaciones y culturas extranjeras, que permiten asegurar un orden internacional más justo y un mejor orden jurídico social en el plano interno" 59 . Se trata, por lo tanto, de una alternativa a los problemas prácticos producto de la aplicación de la norma conflictual ${ }^{60}$, proveyendo jurisdicción más adecuada a las necesidades del comercio ${ }^{61}$ :

Oxford: Hart, 2010, p. 33.

52 "Lex mercatoria's productive relationship with national contract laws was marked by a continuos evolution of contract legislation and adjudication...", CALLIES, Gralf-Peter; ZUMBANSEN, Peer. Op. cit., p. 32.

53 Ibíd., p. 33.

54 "En las últimas décadas estamos contemplando la crisis del legalismo y del formalismo, y el triunfo de la historicidad. Un derecho duro y rígido, voluntariamente impermeable a la realidad exterior, está siendo rápidamente sustituido por otro elástico e, insistimos en ello, soft". GROSSI, Paolo. Op. cit., p. 357-358.

55 GOLDMAN, Berthold. Op. cit., p. 184-185.

56 CARDENA AFANADOR, Walter René. Op. cit., p. 113; PINHEIRO, Luis de Lima. Op. cit., p. $145-147$.

57 GROSSI, Paolo. De la codificación..., p. 358.

58 Ibíd., p. 387-388.

59 WALD, Arnoldo. "A introdução da Lex mercatoria no Brasil e a criação de uma nova dogmática”. Revista de Direito Mercantil, Industrial, econômico e Financeiro. 1995, n 100, p. 20-23.

60 LÓPEZ RODRÍGUEZ, Ana M. Op. cit., p. 94; SBORDONE, Francesco. Contratti internazionali e lex mercatoria. Napoli: Edizioni Scientifiche Italiane, 2008, p. 122-124; MORENO RODRÍGUES, José Antonio. "La nueva lex mercatoria: ¿un fantasma creado por profesores de la Sorbona? Foro de Derecho Mercantil". Revista Internacional. 2003, no 1, p. 112. 61 MORENO RODRIGUEZ, José Antonio. Contratación y arbitraje: contribuciones recientes. 
ya que las reglas de los diferentes sistemas nacionales son adecuadas para las relaciones internas; se contribuiría a la uniformidad del sistema internacional; deja la incompletud y falta de legitimación de la lex mercatoria para un segundo plano ${ }^{62}$.

Además den aplicarse como Derecho de regencia de contratos internacionales ${ }^{63}$, la jurisprudencia arbitral habría reconocido otras funciones a la lex mercatoria: (i) reglas transnacionales materiales sobre la existencia y validez de compromisos arbitrales; (ii) reglas transnacionales de Derecho privado; (iii) reglas materiales relacionadas al mérito de la disputa y como (iv) orden público transnacional ${ }^{64}$.

Cadenas Afanador destaca la efectividad alcanzada en asuntos complejos, neutralidad en la administración de la justicia y valorización de la autonomía individual ${ }^{65}$. A pesar de inicialmente haber sido seductora, la construcción jurídica de la Lex mercatoria puede ser objeto de crítica. Algunas de las principales serían la imprecisión, la generalidad y la falta de unicidad de sus disposiciones y fuentes; la falta de universalidad; su limitada legitimidad (estrictamente vinculada a una clase) y la ausencia de rigor científico y autonomía (dependería del reconocimiento por los diferentes ordenamientos nacionales) ${ }^{66}$. Por otro lado, sus defensores argumentan que aunque no se trate de un sistema autorreferenciado, podría complementarse por el proceso decisorio arbitral; no sería estructurada de forma deductiva pero sí a partir de casos; es previsible en la medida en que las decisiones arbitrales son publicitadas, así como bases de datos y publicaciones sobre el tema; así como poder ser fácilmente actualizada de acuerdo con las necesidades sociales ${ }^{67}$.

Aunque tales críticas suenen meramente académicas, pueden hacerse algunas ponderaciones a partir de ellas. Especialmente cuando se destacan los riesgos inherentes a este modelo: asimetría de protección entre comerciantes y no comerciantes; entre Estados económicamente más desarrollados y otros aún no; la posibilidad de abuso de la autonomía individual; la falta de seguridad en razón de la valorización de la flexibilidad ${ }^{68}$.

Sin embargo, estos no parecerían problemas a enfrentar en el ámbito de la teoría de la Lex mercatoria. Ni siquiera lo sería, según Dasser, la discusión sobre la normatividad de la costumbre. En verdad, ésta se ocuparía de identificarla como ordenamiento autónomo o

Asunción: CEDEP, 2010, p. 54-58.

62 LÓPEZ RODRIGUEZ, Ana M. Op. cit., p. 109-110.

63 FERNÁNDEZ ROZAS, José Carlos. Op. cit., p. 76.

64 LÓPEZ RODRÍGUEZ, Ana M. Op. cit., p. 121-129.

65 CADENA AFANADOR, Walter René. Op. cit., p. 105.

66 Ibíd., p. 106-107.

67 LÓPEZ RODRÍGUEZ, Ana M. Op. cit., p. 105-108.

68 CADENA AFANADOR, Walter René. Op. cit., p. 114. 
como nuevo sistema conflictual que sustituyese el régimen estatal ${ }^{69}$. En otros términos, habría una insistencia en admitir que las cortes arbitrales crearían nuevas normas, en lugar de aplicar costumbres transnacionales ${ }^{70}$.

Debe destacarse preliminarmente que la Lex mercatoria no puede ser entendida como un ordenamiento propio, ajeno o competitivo, con la protección de la persona, fundamento último de cualquier construcción jurídica. Aunque se pueda debatir cuál es el papel del derecho internacional frente al derecho nacional, es vital comprender que ambos se asocian a la protección de la persona, instrumentalizando su libre desarrollo y subsistencia. Ignorar este imperativo lógico sería admitir que se está realizando un ejercicio infinito de metalenguaje, criticando un abordaje jurídico para el simple deleite de comprender mejor el propio derecho.

El punto clave de esta crítica se encuentra en admitir espacio para el ejercicio de las libertades económicas. Como recuerda Rechsteiner, parte de los defensores de la Lex mercatoria argumenta la inaptitud estatal en la reglamentación del comercio internacional por causa de su dificultad en acompañar el ritmo y el desarrollo comercial ${ }^{71}$. Soares agrega la lentitud, la publicidad y el foro estatal privilegiado que incentivaron el desarrollo del arbitraje internacional privado ${ }^{72}$. Además, normalmente se destacan la capacidad privada de producción de normas más flexibles $\mathrm{y}$ adecuadas ${ }^{73}$, y el derecho de elegir un Derecho no nacional a ser aplicado a un contrato internacional ${ }^{74}$. La impresión que se daba, en opinión de De Ly, era que los defensores de la lex mercatoria buscaban limitar el fin y los efectos de las normas imperativas de Derecho nacional, sin existir un conjunto autónomo de reglas imperativas que protegiese sus propios intereses ${ }^{75}$. Al final, la definición del contenido normativo por los propios interesados tiene "costos" y atendiende los intereses que deben ser sopesados ${ }^{76}$.

69 Dasser, Felix. Lex mercatoria - Critical Comments on a Tricky Topic. APPELBAUM, P.; FELSTINER, W. L. F.; GESSNER, V. (Eds.). Rules and Networks, The Legal Culture of Global Business Transactions. Oxford: Hart, 2002, p. 189-191.

70 DE LY, Filip. Op. cit., p. 66.

71 RECHSTEINER, Beat Walter. Direito internacional privado: teoria e prática. $7^{\text {a }}$ ed. São Paulo: Saraiva, 2004, p. 66.

72 SOARES, Guido Fernando Silva Soares. "El orden público en los contratos internacionales". Revista de Direito Mercantil, Industrial, Económico e Financeiro. 1984, nº, p. 127-128.

73 Goode menciona las razones que motivarían a las partes a no optar por una ley nacional: contenido no laico, necesidad de neutralidad, identidad de legislaciones, dificultad de elección de la ley aplicable, la elección de una determinada ley es considerada insatisfactoria, legislación nacional encarada con desconfianza por los árbitros; la Corte arbitral está comprometida con la noción de Lex mercatoria. GOODE, Roy. Usage and its reception..., Op. cit., p. 30.

74 ELCIN, Mert. The applicable law to International Commercial contracts and the status of lex mercatoria: with a special emphasis on choice of law rules in the European Community. Boca Raton: Dissertation.com, 2006, p. 77-78.

75 DE LY, Filip. Op. cit., p. 286.

76 JOHNS, Fleur. "Performing party autonomy". Law and contemporary problems. 2008, vol 
Debe reconocerse que el mercado no es capaz de organizar solo toda actividad económica. Además, de un espacio de libertad, existe un espacio para la dirección ya sea del Estado -corrigiendo las "inoperancias" destacadas por Nusdeo ${ }^{77}$-, sea al reconocer límites a la propia libertad, consagrando otros valores que condicionan la actividad económica. Además, está quien sustenta la existencia de un orden público transnacional para autorizar el control de la Lex mercatoria por los propios árbitros ${ }^{78}$.

Lo interesante de esta conclusión es que otrora sirvió para destacar la insuficiencia del Estado. Si en el pasado las "fronteras" eran colocadas por el "triunfo" de la "política", hoy lo son por la consagración de la "tecnología" y la economía global ${ }^{79}$. De ahí que la comprensión del papel del Estado y/o del Mercado, no pueda ser absoluta so pena de convertirse en profesión de fe más que en explicación normativa. Así, por ejemplo, Forgioni afirma que "las contrataciones se dan dentro de los límites puestos por el ordenamiento estatal; el mercado está formado por reglas exógenas y no por sus propias determinaciones" 80 .

La relación que termina instaurándose es, de alguna forma, simbiótica. De un lado, el Estado no puede simplemente ignorar la existencia del fenómeno denominado Lex mercatoria; del otro, el fenómeno de la Lex mercatoria no puede prescindir del Estado. Una de esas posibles relaciones se da, por ejemplo, como recuerda Reschteiner, cuando no se vincula el Estado a las prácticas comerciales que ofendan su orden público ${ }^{81}$.

Virally comenta justamente que la lex mercatoria no consigue desligarse completamente del orden jurídico estatal. Según el autor, aunque se asuma la formación a partir de ella de un Derecho transnacional, él dependería de la tolerancia del orden interno, por entre otras reglas del orden público ${ }^{82}$. Además, conviene recordar que el hecho de que el Orden Público incida (para controlar) en el contenido de la lex mercatoria, no tendría la facultad de limitarle o negarle juridicidad. ${ }^{83}$

De Ly resalta, a comienzos de la década de 1990, que la lex

71, p. $243-271$.

77 NUSDEO, Fábio. Fundamentos para uma codificação do Direito econômico. São Paulo: RT, 1995 , p. 23.

78 JAQUET, Jean-Michel; DELEBECQUE, Philippe. Droit du commerce international. París: Dalloz, 1997, p. 92.

79 GROSSI, Paolo. História da propriedade e outros ensaios. Rio de Janeiro: Renovar, 2006, p. $107,118$.

80 FORGIONI, Paula A. Teoria geral dos contratos empresariais. São Paulo: RT, 2009, p. 81.

81 RECHSTEINER, Beat Walter. Op. cit., p. 69.

82 VIRALLY, Michel. El devenir del Derecho internacional: ensayos escritos al correr de los años. México: Fondo de Cultura Económica, [199_?], p. 575; 583. En el mismo sentido: DASSER, Felix. "Lex Mercatoria - Critical Comments on a Tricky Topic". In APPELBAUM, P.; FELSTINER, W. L. F.; GESSNER, V. (eds.). Rules and Networks, The Legal Culture of Global Business Transactions. Oxford: Hart, 2002, p. 184.

83 OPPETIT, Bruno. Op. cit., p. 60. 
mercatoria no era frecuentemente aplicada por las Cortes nacionales y que los pocos casos entonces existentes no podrían ser interpretados como reconocimiento ${ }^{84}$. Recuérdese que el UCC prevee no sólo la obligatoriedad de las costumbres, sino también la Law Merchant (Lex mercatoria) como una de sus fuentes subsidiarias (art. 1-103, b) ${ }^{85}$. Esta también sería la tendencia de la legislación arbitral brasileña (art. $2^{\circ}$, $\left.2^{\circ}\right)^{86}$. Además de esto, el Estado participa de actos internacionales en los que acaba reconociendo su existencia. Un ejemplo, aunque nunca haya entrado en vigor, es la Convención Interamericana de México 1994 (CIDIP V) que previó la apertura para que se admitan como el Derecho escogido por las partes para regir el contrato, no sólo el Derecho "positivo" sino también las costumbres, los principios generales del Derecho comercial internacional y los usos y prácticas del comercio internacional (art. 10). Esta disposición es identificada por Maekelt como consagradora de la Lex Mercatoria ${ }^{87}$. Madruga Filho, por otro lado, al interpretar el art. 17 de la Convención comprende que habría limitación de la elección de los contratantes al Derecho estatal, aunque concuerde que la Lex mercatoria pudiese ayudar a componer el Derecho aplicable, a tenor con el art. $10^{88}$.

Esta relación trae otro cuestionamiento: el contenido normativo que compone la lex mercatoria. La doctrina, de un modo general, menciona ampliamente sus fuentes: prácticas comerciales, jurisprudencia arbitral, usos y cláusulas padronizadas, trabajo de peritos en el ámbito de organizaciones internacionales, guías profesionales y códigos de conducta ${ }^{89}$. Está quien agrega los tratados internacionales ${ }^{90}$ o hace una referencia más abarcativa y engloba los principios generales de derecho ${ }^{91} \mathrm{o}$, incluso, menciona instrumentos específicos como los Principios UNIDROIT, los INCOTERMS, las UCPs, las leyes modelo de

84 DE LY, Filip. Op. cit., p. 266.

85 "(b) Unless displace by the particular provisions of [the Uniform Commercial Code], the principles of law and equity, including the law merchant and the law relative to capacity to contract, principal and agent, estoppel, fraud, misrepresentation, duress, coercion, mistake, bankruptcy, and other validating or invalidating cause supplement its provisions".

86 FRADERA, Véra Maria Jacob de. "Aspectos problemáticos na utilização da arbitragem privada na solução de litígios relativos a direitos patrimoniais disponíveis - Comentários a Lei de Arbitragem". In: MARQUES, Claudia Lima; ARAUJO, Nadia de. (eds.). O novo direito internacional: estudos em homenagem a Erik Jayme. Rio de Janeiro: Renovar, 2005 p. 418-419. 87 MAEKELT, Tatiana B. de. "La flexibilización del contrato internacional en La Convención Interamericana sobre Derecho aplicable a los Contratos Internacionales”. In: CASELLA, Paulo Borba (ed.). Dimensão Internacional do Direito: estudos em homenagem a G. E. do Nascimento e Silva. São Paulo: LTr, 2000, p. 269-276.

88 MADRUGA FILHO, Antenor Pereira. "A CIDIP-V e o Direito aplicável aos contratos internacionais". Revista de Direito de Empresa. 1996, n 1, p. 95, 101.

89 BRITO, Maria Helena. Op. cit., p. 119.

90 CARDENA AFANADOR, Walter René. "Impacto en Colombia de la Lex mercatoria". Revista electrónica de difusión de la Universidad Sergio Arboleda. 2006, n 11, p. 1-21.

91 FELDSTEIN DE CARDENAS, Sara. Op. cit., p. 168-172. 
la UNCITRAL ${ }^{92}$ y los Principios Europeos del Derecho Contractual ${ }^{93}$. Por otro lado, también están aquellos que niegan el carácter de fuente a los tratados ${ }^{94}$.

Ese conjunto de prácticas reiteradas, uniformemente acatada por los agentes del comercio internacional superaría, entonces, "las barreras de los derechos nacionales para consagrar una forma de derecho supranacional"95. Para ejemplificar esta afirmación pueden ser citados la letra de cambio (Bill of Exchange) cuyo origen se remontaría a la Edad Media ${ }^{96}$ y los llamados incoterms que regulan la transferencia de riesgos y costos de operaciones de compra y venta internacional. Tales "cláusulas padrón” acabaron siendo consolidadas por la Cámara de Comercio Internacional de París, y pasaron por diversas actualizaciones, siendo la más reciente de ellas en 2010. Tales figuras ganaron tamaña importancia en el derecho contractual internacional que influyeron en los negocios internos a pesar de su origen y fundamento ${ }^{97}$.

Pueden ser citados, incluso, los modelos de contratos (CCI, UNCITRAL, etc.) que representan un conjunto de reglas destinadas a proveer las bases de negociaciones posteriores y que culminaron siendo ampliamente utilizadas por el Derecho internacional. Habría, según Carreau y Juillard, una especie de autoridad de propagación y capacidad de instrumentalizar los principios generales del derecho internacional económico $^{98}$. Por otro lado, la naturaleza costumbrista de esas reglas normalmente es enfatizada:

...lo que constituye propiamente la 'nueva lex mercatoria' no es otra cosa que un conjunto de reglas de comportamiento y cláusulas de interpretación uniforme y típicas que se generan de manera constante y reiterada en el comercio internacional y que son asumidas por los particulares en virtud de la existencia de una convicción de su carácter vinculante: lo que genéricamente se califica de 'usos y costumbres del comercio internacional, pero que, en un análisis más detenido,

92 CARLINI, Gabriel A. El contrato de compraventa internacional de mercaderías. Buenos Aires: Ábaco, 2010, p. 41-43.

93 BRITO, Maria Helena. "Portugal". In: ESPLUGUES MOTA, Carlos; HARGAIN, Daniel; PALAO MORENO, Guillermo (eds.). Derecho de los contratos internacionales en Latinoamérica, Portugal y España. Madrid: Edisofer, 2008, p. 674.

94 İdem

95 GREBLER, Eduardo. “O contrato internacional no Direito de empresa”. Revista de Direito Mercantil. 1992, n 85 , p. 27.

96 DRAHOS, Peter; BRAITHWAITE, John. “The globalization of regulation”. The Journal of Political Philosophy. 2001, vol 9, nº 1, p. 110.

97 GLITZ, Frederico Eduardo Zenedin. "Transferência do risco contratual e incoterms: breve análise de sua aplicação pela jurisprudência brasileira”. In CORTIANO JUNIOR, Eroulths; et al. (eds.). Apontamentos críticos para o Direito civil brasileiro contemporâneo II - Anais do Projeto de Pesquisa Virada de Copérnico. Curitiba: Juruá, 2009, p. 111-139.

98 CARREAU, Dominique; Juillard, Patrick. Droit international économique. $3^{\text {a }}$ ed. Paris: Dalloz, 2007, p. 13. 
comprende fundamentalmente: los llamados 'términos comerciales uniformes', las 'condiciones generales de venta' aceptadas en ciertos sectores del comercio internacional, los 'contratos tipo' para la venta de ciertos productos, etc. ${ }^{99}$.

Tal abordaje realiza una escasa distinción entre las distintas fuentes y sus diferencias conceptuales. Así, por ejemplo, al someterse al mismo enfoque prácticas costumbristas, modelos contractuales, codificaciones privadas y principios generales, se da tratamiento uniforme a distintos fenómenos. Por lo menos, ésta es una crítica acerca de la impresión de su contenido. Esta preocupación, expresa Gaillard, adquiere relevancia cuando se imaginan las consecuencias de libertad/deber de los árbitros de definir el derecho aplicable al caso concreto. Así, dependiendo del tratamiento legal, los árbitros podrían escoger las reglas de derecho que resulten aplicables teniendo en cuenta las costumbres; elegir simplemente las reglas de derecho o, incluso, tener en cuenta los usos y costumbres del comercio internacional (modelo UNICTRAL) ${ }^{100}$. La precisión de lo que vendrían a componer las costumbres, estrictamente, y los usos y costumbres del comercio internacional podrían, por lo tanto, tener repercusión directa en la conclusión de los árbitros. En razón de eso, parece más adecuado limitar el espectro de lo que se entienda como lex mercatoria para aquellas prácticas consuetudinarias que forman parte del pretendido derecho comercial transnacional ${ }^{101}$.

Además, no se puede confundir la naturaleza de cada una de esas fuentes ya que no todas son verdaderamente consuetudinarias. Si por un lado parece ser posible aceptar la existencia de costumbres mandatorias ${ }^{102}$, aunque estén sujetas a algún tipo de control, por otro lado se puede decir que todas las compilaciones realizadas son verdaderamente costumbristas. Pinheiro concluye que sólo podrían ser consideradas fuentes del Derecho autónomo del comercio internacional aquellas con una nítida naturaleza consuetudinaria, aquellas creadas por la jurisprudencia arbitral y por centros autónomos con base en la autonomía privada que tendrían vigencia independiente de la existencia de un ordenamiento propio. Se excluirían, así, los regulamientos arbitrales, los PICC, los modelos contractuales, las cláusulas modelo, etc. ${ }^{103}$.

Se debe tener en mente también que la construcción puramente jurisprudencial o basada en precedentes no es del todo adecuada, ya que: (i) aborda exclusivamente casos anómalos; (ii) normalmente está

99 FERNÁNDEZ ROZAS, José Carlos. Ius mercatorum: autorregulación y unificación del Derecho de los negocios transnacionales. Madrid: Colegios Notariales de España, 2003, p. 89. 100 GAILLARD, Emmanuel. Op. cit., p. 211.

101 GOODE, Roy; KRONKE, Herbert; MCKENDRICK, Ewan. Op. cit., p. 06; 35; 38

102 DALHUISEN, J. H. Dalhuisen on transnational and comparative comercial, financial and trade law. $3^{\text {a }}$ ed. Oxford: Hart, 2007, p. 228-231.

103 PINHEIRO, Luís de Lima. Direito Comercial..., p. 208-210. 
centrada en cuestiones procesales y (iii) no se constituye en precedentes vinculativos ${ }^{104}$. Inclusive, más allá de eso, si la Lex mercatoria tiene una naturaleza costumbrista, ¿por qué dependería de la libertad contractual? Por lo tanto, existen muchas puertas abiertas para que se pueda imaginar la existencia de un sistema propio.

If the contract expressly directs the arbitrator to apply the lex mercatoria, or if he conceives that the circumstances justify him in treating such a directive as implicit, he will find a way of doing so, notwithstanding the fragmentary nature of the norms so far established. But this is only a small part of the story. The purpose of a commercial legal order is to regulate transaction, not awards or judgments. For the businessman, proceedings in court or arbitration are a wretched last resort, to be avoided at almost any cost and in fact they are avoided to inform him before any dispute has arisen what he can or must do next. If a dispute does arise he needs to be told whether he can insist or must yield, and how much room he has for maneuver. When asking such a question, the last answer which a businessman wants to hear is that it is a good question $^{105}$.

Además, cuando el texto de Mustill fue escrito, apenas 20 (veinte) "principios" podrían identificarse, por la jurisprudencia arbitral ${ }^{106}$, con la lex mercatoria. Estas constataciones generan un cuestionamiento de otro orden.

\section{LEX MERCATORIA: ¿CONVENIENCIA Y OPORTUNIDAD?}

Talvez, en este aspecto, se pueda utilizar la conclusión de Moreno Rodríguez de que, independientemente de su naturaleza, conviene estudiar la lex mercatoria ya que ella estará en el centro del desarrollo del Derecho contractual en el siglo XXI ${ }^{107}$.

Así, al lado de toda discusión sobre la autonomía de la Lex mercatoria como sistema normativo y de su conjunto de fuentes, también parece indispensable pensar la conveniencia de la adopción (aunque en parte) de un sistema autónomo para la regencia de relaciones contractuales comerciales.

Eso porque, más que como un sistema normativo autónomo, podría presentarse como una forma de producción normativa ${ }^{108}$, basada

$\overline{104 \text { Ibíd., p. 190-191. }}$.

105 MUSTILL, Michael. The new Lex Mercatoria: The First Twenty-five Years, Arbitration International. 1998, vol 4, p. 116-117.

106 Ibíd, p. 110-114.

107 MORENO RODRÍGUEZ, José Antonio. Op. cit., p. 124.

108 MOSSET ITURRASPE, Jorge; PIEDECASAS, Miguel A. Contratos: aspectos generales. Buenos Aires: Rubinzal-Culzoni, 2005, p. 121. 
en la creatividad y libertad privada y sujeta a controles normativos estatales o no, como se demostrará.

Delaume, por ejemplo, argumenta que tratándose de contratos públicos, celebrados entre Estados e inversores, el sistema convencional existente estaría más adaptado a las necesidades prácticas que cualquier forma de Lex mercatoria que eventualmente pudiese pensarse ${ }^{109}$. Davies, por otro lado, en un texto más contemporáneo, sustenta que la ya citada Convención del Cabo representaría un nuevo tipo de Lex mercatoria para transacciones internacionales aseguradas ${ }^{110}$.

También es interesante la afirmación de Galgano de que la lex mercatoria engendra un nuevo tipo de legitimación en el Mercado ya que aquella (democrática) fue padronizada para la formación estatal. En suma, una sociedad global y sin la presencia del Estado no habría manera de reproducirla. Así, destaca que aunque la sociedad globalizada no sea capaz de participar políticamente de un ambiente global, puede crear derecho ${ }^{111}$.

El discurso en torno a la lex mercatoria está, sin embargo, marcado por su falta de objetividad. Calvo Caravaca y Carrascosa González destacan por ejemplo, intereses corporativos de aquellos que la defienden, sean profesores o grandes conglomerados internacionales ${ }^{112}$. Shapiro y Sweet añaden a los abogados ${ }^{113}$ y Fernández Rozas, Arena García y Miguel Asensio identifican la existencia de "marketing" y construcciones "pseudo doctrinarias" que no buscarían "otra cosa que la presencia en el mercado de la solución de controversias mercantiles internacionales"114.

Al lado de la incerteza de sus motivaciones, existen dudas acerca de su instrumentalización. Paulsson, por ejemplo, constata la aplicación del concepto de lex mercatoria en los laudos arbitrales de la CCI, principalmente en dos sentidos diferentes (como reglas suficientes a

109 DELAUME, Georges. "Comparative analysis as a basis of la in State Contracts: the myth of the Lex mercatoria”. Tulane Law Review. 1989, vol 63, p. 611.

110 DAVIES, Iwan. "The new lex mercatoria: international interest in mobile equipment". International and Comparative Law Quarterly. 2003, vol 52, p. 154.

111 GALGANO, Francesco. "Lex mercatoria e legittimazione". Sociologia del Diritto. 1995, no 2-3, p. 201-202.

112 CALVO CARAVACA, Alfonso-Luis. "Los contratos internacionales y el mito de la nueva lex mercatoria". Cadernos da Escola de Direito e Relações Internacionais da UniBrasil, n. 12, 2010, p. 15-16.

113 "If, however, we look at the world as containing not just two players - those who wish to contract and governments - but instead three players, those who wish to contract, governments, and the legal profession - the freedom picture may not be as clear. It is here that the arguable, but not proved, thesis of globalization as Americanization becomes relevant. To the extent that the American style of contract writing and disputing is becoming global, global freedom of contract maybe, along a certain dimension, illusory or purchased at a very high cost. The lawyers may have become far freer than the contracting parties". SHAPIRO, Martin; SWEET, Alec Stone. On law, politics \& judicialization. Oxford: Oxford press, 2002, p. 322.

114 FERNÁNDEZ ROZAS, José Carlos; ARENAS GARCÍA, Rafael; Miguel Asensio, Pedro Alberto. Derecho de los negocios internacionales. $2^{\text {a }}$ ed. Madrid: Iustel, 2009, p. 40. 
regir un contrato y como reflejo de los usos comerciales y principios generales del comercio ${ }^{115}$. Grande, en un estudio sobre laudos arbitrales CCI más actualizados, demuestra que la lex mercatoria no es una creación arbitral ni sirve autónomamente ya que en la mayor parte de los laudos encontraba apoyo en el derecho local, usos y costumbres comerciales, principios generales de Derecho, etc. Además, los árbitros no la asociaban a la idea de un ordenamiento jurídico autónomo ${ }^{116}$.

Lo único constante en las decisiones arbitrales es la remisión a los usos y las costumbres, y el reconocimiento de la universalidad de principios generales del comercio mayormente plasmados en instrumentos internacionales (convenciones internacionales $\mathrm{o}$ principios UNIDROIT). Como aquellos principios surgen mediante la internacionalización del derecho doméstico, esto podría indicar que no existe un derecho autónomo especialmente creado al margen de los derechos locales. De lo anterior, y debido a que los usos y las costumbres se desarrollan junto con el derecho de fuente local, podría postularse que el derecho del comercio internacional se estaría gestando en estrecha relación con los derechos domésticos ${ }^{117}$.

Drazohal entiende que sería un mito la generalizada adopción de la lex mercatoria como reglamento aplicable al arbitraje. Además, advierte que normalmente cuando se hace referencia a ella se trata de un complemento a la legislación nacional ${ }^{118}$, la misma constatación se da en asociaciones profesionales ${ }^{119}$. Davidson, analizando otra base de datos, llega a constataciones semejantes: las cortes arbitrales se abstendrían de utilizar la lex mercatoria para regir los conflictos, incluso cuando fueran instadas por las propias partes ${ }^{120}$. Dasser también es enfático: la aplicación de la lex mercatoria como alternativa al derecho doméstico es rara, aunque la discusión se haya prolongado por más de cincuenta años $^{121}$. En el mismo sentido, concluye Dalhuisen ${ }^{122}$.

115 PAULSSON, Jan. "La lex Mercatoria dans l' Arbitrage C.C.I”. Revue d'Arbitrage. 1990, p. 55-100.

116 GRANDE, Silvana. "La Lex Mercatoria en los laudos de la Cámara de Comercio Internacional”. Díkaion. 2008, vol 22, n 17, p. 240-241.

117 Ibíd., p. 241.

118 DRAHOZAL, Christopher R. "Busting arbitration myths". Kansas Law Review. 2008, v. 56, 2008, p. 672-673.

119 DRAHOZAL, Christopher r. "Private ordering and international commercial arbitration". Penn State Law Review. 2009, vol 113, n 4, p. 1031-1050.

120 DAVIDSON, Matthew T. The Lex Mercatoria in Transnational Arbitration: An Analytical Survey of the 2001 Kluwer International Arbitration Database [online]. Disponible en: $<w w w-$ cisgw3.law.pace.edu/cisg/biblio/Davidson.html>

121 DASSER, Felix. "Mouse or monster? Facts and figures on lex mercatoria". In: ZIMMERMANN, Reinhard (eds.). Globalisierung und Entstaatlichung des Rechts. Tübingen: Mohr Siebeck, 2008, p. 153.

122 DALHUISEN, J. H. Op. cit., p. 239. 
Aunque su aplicación no sea tan abundante como podría pensarse, la lex mercatoria engendra la problemática del contenido de la decisión arbitral. Aunque se traten de derechos disponibles, como en el arbitraje regido por el derecho brasilero, es necesario tener noción de su imprecisión y vaguedad (si no es en cuanto a las fuentes, al menos en cuanto al contenido). Park, por ejemplo, defendía cierto control de su objeto, aunque no bajo otras fórmulas vacías (orden público, por ejemplo ${ }^{123}$. La mayor cuestión no es la búsqueda por decisión justa ${ }^{124}$ sino adecuada a ciertos valores. Entonces es relevante la comprensión de cómo la lex mercatoria parece relacionarse con los diferentes ordenamientos que encuentra.

Pinheiro, por ejemplo, sustenta que la lex mercatoria podría ser aplicada directamente en la relación controvertida independientemente de su recepción por parte del Ordenamiento Estatal ${ }^{125}$. Esto se daría por medio de dos procesos: (i) por aplicación de normas de conflicto, es decir, producto de la "proposiciones conflictivas de derecho transnacional de arbitraje"126 y (ii) por aplicación de los usos y costumbres del comercio internacional, aunque no fuese necesario hacer distinción entre las costumbres nacionales e internacionales para esta finalidad ${ }^{127}$, respetadas las normas imperativas. Sus funciones serían producto de cada una de sus fuentes, así las costumbres comerciales internacionales serían relevantes para la interpretación, la integración de los contratos y la definición del contenido del contrato ${ }^{128}$.

Por otro lado, parece verosímil sustentar que el papel de la lex mercatoria estaría más ligado al método de elección de una fuente normativa aplicable al caso concreto ${ }^{129}$ que al reconocimiento de un conjunto de reglas (autónomo o no) de existencia independiente. Como advierte Gaillard, la lex mercatoria estaría definida por las fuentes y no por su contenido ${ }^{130}$. De esta forma, en la búsqueda del derecho

123 PARK, William W. "Control mechanism in the development of a modern lex mercatoria". CARBONNEAU, Thomas (eds.). Lex mercatoria and arbitration: a discussion of the new law merchant. New York: Transnational Juris, 1990, p. 138.

124 "Arbitrators do not make up the law as they go along, and contrary to popular view, most arbitrators do not look first of all for compromise. International arbitrators do seek to achieve just results within a legal framework, and that framework is by definition wider than the frontiers of any state. To me, this is the vision, the promise, and the usefulness of lex mercatoria". LOWENFELD, Andreas F. "Lex mercatoria" [online]. An Arbitrator's View, arb. Internl., 1990, p. 150. Disponible en: zwww.trans-lex.org/output.php?docid=126000>

125 PINHEIRO, Luís de Lima. Direito Comercial..., p. 216.

126 Ibíd., p. 217

127 Ibíd, p. 220.

128 Ibíd, p. 227.

129 "Les regles transnationales ne résultent pas d'une liste mais d'une méthode. Lorsqu'ils se trouvent confrontés a la nécessité de faire application de regles transnationales, par exemple parce que les parties l'int voulu". GAILLARD, Emmanuel. "Trente ans de Lx mercatoria puor une application sélective de la méthode des príncipes généraux du droit”. Journal du Droit international. 1995, $\mathrm{n}^{\circ} 1,1995$, p. 22.

130 GAILLARD, Emmanuel. “Transnational Law: A Legal System or a Method of Decision 
aplicable, los árbitros y las partes no estarían desprovistos de fuentes de consulta y sería posible el recurso a las Convenciones, a la doctrina $\mathrm{y}$ a los trabajos de organismos internacionales ${ }^{131}$. La solución dada a un caso no siempre encontrará consenso dadas las particularidades de las diferentes familias y de los principios regionales ${ }^{132}$.

No se trata de cuestionar la función a ser ejercida por la Lex mercatoria, es decir, si es interpretativa e integrativa del negocio jurídico ${ }^{133}$ y eventualmente subsidiaria del orden estatal ${ }^{134}$ o un conjunto que se desprende de la comparación entre varios ordenamientos ${ }^{135}$. Pero sí de reconocer un determinado "derecho" aplicable a una determinada situación por medio de un método idóneo que tenga en consideración las diversas fuentes existentes y la situación concreta en términos de derecho comparado. Por lo tanto, se trataría de un método de decisión ${ }^{136}$. Tal vez sea en este sentido que se pueda adoptar el posicionamiento de Leduc cuando afirma que no están totalmente desprovistos de razones aquellos que sustentan que no existe la lex mercatoria pero que sin lugar a dudas existiría contemporáneamente una tendencia de estimular el surgimiento de costumbres y prácticas contractuales ${ }^{137}$.

Aunque se pueda cuestionar tal amplitud de autonomía a las normas que forman la llamada lex mercatoria, parece razonable destacar la función normativa ejercida por cada una de ellas ${ }^{138}$. De esa forma, tratándose de costumbres contractuales sería posible afirmar que su papel en el negocio dependería de la comprensión que se tiene de su normatividad en cada uno de los sistemas apreciadores. De hecho, no existiría un contrato "sans loi" pero esta ley no se resume al texto legislativo sino al "derecho" aplicable a él ${ }^{139}$.

\footnotetext{
Making?". Arbitration Internationl. 2001, vol 17, n 1, p. 61.

131 GAILLARD, Emmanuel. Trente ans de lex..., p. 25-26.

132 Ibíd., p. 30.

133 FERNÁNDEZ ROZAS, José Carlos; ARENAS GARCÍA, Rafael; Miguel AsensioN, Pedro Alberto. Op. cit., p. 41.

134 PINHEIRO, Luís de Lima. O direito autónomo..., p. 396.

135 "un conjunto normativo que no deriva de un único ordenamiento estatal que se desprende de la comparación de los Derechos nacionales, de fuentes internacionales tales como los convenios internacionales, o de la jurisprudencia de los tribunales internacionales". FERNÁNDEZ ROZAS, José Carlos; ARENAS GARCíA, Rafael; Miguel Asensio, Pedro Alberto. Op. cit., p. 41.

136 GAILLARD, Emmanuel. Transnational Law..., p. 62.

137 LEDUC, Antoine. "L'emergence d'une nouvelle lex mercatoria a l'enseigne des príncipes d'UNIDROIT relatifs aux contracts du commerce international: these et antithese". Revue Juridique Thémis. 2001, vol 35, p. 450.

138 CARA, Jean-Yves de. "International trade and the rule of law". Mercer Law Review. 2007, vol 58, p. 1380.

139 Adviértase que este raciocinio no es unánime. El propio Gaillard, por ejemplo, mantiene que en situaciones en que las partes de un litigio arbitral pretenden la aplicación de un "Derecho" (law") y no de meras reglas de derecho ("rules of law"), el árbitro podría hacer uso del Derecho transnacional en condiciones similares a las de un ordenamiento autónomo, aunque no reconozca la lex mercatoria como un ordenamiento genuino. GAILLARD, Emmanuel. Op. cit., p. 71.
} 
En el caso brasilero este "derecho incluye las costumbres como fuentes normativas plenas, inclusive capaces de crear lazos obligatorios entre los contratantes. Este papel dependerá del espacio de libertad que es otorgado a los particulares para la creación normativa.

\section{CONCLUSIONES}

Luego del transcurso de esas razones, llega el momento en que se le debe asignar un papel más contemporáneo a la lex mercatoria.

Percíbase, entonces, que por un lado se dé el hecho de que el proceso de globalización jurídica engendra la pérdida de exclusividad estatal de afirmación negativa y, por el otro, no puede ser entendido como sinónimo de ausencia de tutela jurídica, sino de ampliación de la comprensión del derecho.

Deben hacerse algunas aclaraciones; en primer lugar, no se niega el papel de la reglamentación estatal y local, sino ésta deja de ser la única forma de normativización. En segundo lugar, la misma internacionalización que permite este papel, central y no excluyente, también brinda los mecanismos necesarios para su control así como la adecuación del derecho contractual como un todo.

Así, junto con los mecanismos típicamente individuales (autonomía privada) y estatales (orden público y lois de police), surgen mecanismos internacionales de control del contenido negociable. La globalización jurídica, por lo tanto, no necesariamente es unilateral o "perversa". De este modo se puede asegurar que disposiciones contractuales proteccionistas y derechos fundamentales y humanos prevalecen sobre determinadas costumbres.

La ley y la voluntad no son las únicas fuentes de legitimación. Apenas son fuentes de contenido normativo existente dentro de un sistema plural.

\section{RESUMEN BIOGRÁFICO}

Frederico E. Z. Glitz es Abogado y profesor de Derecho Internacional Privado en el Centro Universitario Curitiba (UNICURITIBA), Brasil. Profesor de la Maestría en Derecho de la Universidad Comunitaria de Chapecó (UNOCHAPECO), Brasil.

\section{REFERENCIAS BIBLIOGRÁFICAS}

BERGER, Klaus Peter. The creeping codification of the new Lex mercatoria. $2^{\text {a }}$ ed. New York: Wolters Kluwer, 2010, p. 146.

BRITO, Maria Helena. "Portugal”. In: ESPLUGUES MOTA, Carlos; HARGAIN, Daniel; PALAO MORENO, Guillermo (eds.). Derecho de los contratos internacionales en Latinoamérica, Portugal y España. Madrid: 
Edisofer, 2008, p. 665-733.

BRITO, Maria Helena. Direito do comércio internacional. Coimbra: Almedina, 2004.

CALVO CARAVACA, Alfonso-Luis. "Los contratos internacionales y el mito de la nueva lex mercatoria". In: Cadernos da Escola de Direito e Relações Internacionais da UniBrasil. 2010, nº 12, p. 1-20.

CALLIESS, Gralf-Peter; ZUMBANSEN, Peer. Rough consensus and running code: a theory of transnational private law. Oxford: Hart, 2010.

CARA, Jean-Yves de. "International trade and the rule of law". Mercer Law Review. 2007, vol 58, p. 1380.

CARDENA AFANADOR, Walter René. "Impacto en Colombia de la Lex mercatoria". Revista electrónica de difusión de la Universidad Sergio Arboleda. 2006, n ${ }^{\circ}$ 11, p. 1-21.

CARDENA AFANADOR, Walter René. "La nueva lex mercatoria: un caso pionero en la globalización del derecho". Papel Político. 2001, n 13, out. p. 110-111.

CARLINI, Gabriel A. El contrato de compraventa internacional de mercaderías. Buenos Aires: Ábaco, 2010.

CARREAU, Dominique; Juillard, Patrick. Droit international économique. $3^{\mathrm{a}}$ ed. Paris: Dalloz, 2007.

DALHUISEN, J. H. "Custom and its revival in transnational private la". Duke Journal of comparative and international Law. 2008, vol 18, p. 339370.

DALHUISEN, J. H. Dalhuisen on transnational and comparative comercial, financial and trade law. $3^{\mathrm{a}} \mathrm{ed}$. Oxford: Hart, 2007.

DASSER, Felix. "Lex Mercatoria - Critical Comments on a Tricky Topic". In APPELBAUM, P.; FELSTINER, W. L. F.; GESSNER, V. (eds.). Rules and Networks, The Legal Culture of Global Business Transactions. Oxford: Hart, 2002.

DASSER, Felix. "Mouse or monster? Facts and figures on lex mercatoria". In: ZIMMERMANN, Reinhard (eds.). Globalisierung und Entstaatlichung des Rechts. Tübingen: Mohr Siebeck, 2008, p. 153.

DAVIDSON, Matthew T. The Lex Mercatoria in Transnational Arbitration: An Analytical Survey of the 2001 Kluwer International Arbitration Database [online]. Disponible en: <www-cisgw3.law.pace. 
edu/cisg/biblio/Davidson.html>

DAVIDSON, Matthew T. The Lex Mercatoria in Transnational Arbitration: An Analytical Survey of the 2001 Kluwer International Arbitration Database [online]. Disponible en: <www-cisgw3.law.pace. edu/cisg/biblio/Davidson.html>

DAVIES, Iwan. "The new lex mercatoria: international interest in mobile equipment”. International and Comparative Law Quarterly. 2003, vol 52, p. 151-176.

DELAUME, Georges. "Comparative analysis as a basis of la in State Contracts: the myth of the Lex mercatoria". Tulane Law Review. 1989, vol 63, p. 575-611.

DE LY, Filip. International business law and lex mercatoria. Amsterdam: North-Holland, 1992.

DRAHOS, Peter; BRAITHWAITE, John. "The globalization of regulation". The Journal of Political Philosophy. 2001, vol 9, nº 1, p. 663 677.

DRAHOZAL, Christopher r. "Private ordering and international commercial arbitration". Penn State Law Review. 2009, vol 113, no 4, p. 1031-1050.

DRAHOZAL, Christopher R. "Busting arbitration myths". Kansas Law Review. 2008, v. 56, 2008, p. 663-677.

ELCIN, Mert. The applicable law to International Commercial contracts and the status of lex mercatoria: with a special emphasis on choice of law rules in the European Community. Boca Raton: Dissertation.com, 2006.

FELDSTEIN DE CÁRDENAS, Sara. Contratos internacionales. Contratos celebrados por ordenador: Autonomía de la voluntad: Lex mercatoria. Buenos Aires: Abeledo-Perrot, 1995.

FERNÁNDEZ ROZAS, José Carlos. "Lex mercatoria y autonomía conflictual en la contratación internacional". In: Anuario Español de Derecho Internacional Privado. Madrid: Iprolex, 2004, tomo 4, p. 35-78.

FERNÁNDEZ ROZAS, José Carlos. Ius mercatorum: autorregulación y unificación del Derecho de los negocios transnacionales. Madrid: Colegios Notariales de España, 2003.

FERNÁNDEZ ROZAS, José Carlos; ARENAS GARCÍA, Rafael; Miguel Asensio, Pedro Alberto. Derecho de los negocios internacionales. $2^{\mathrm{a}}$ ed. Madrid: Iustel, 2009. 
FORGIONI, Paula A. Teoria geral dos contratos empresariais. São Paulo: RT, 2009.

FRADERA, Véra Maria Jacob de. "Aspectos problemáticos na utilização da arbitragem privada na solução de litígios relativos a direitos patrimoniais disponíveis - Comentários a Lei de Arbitragem". In: MARQUES, Claudia Lima; ARAÚJO, Nadia de. (eds.). O novo direito internacional: estudos em homenagem a Erik Jayme. Rio de Janeiro: Renovar, 2005 p. 418-419.

GAILLARD, Emmanuel. "La distinction des principles généraux du Droit et des usages du commerce international". In Etudes offertes a Pierre Bellet. París: Litec, 1991.

GAILLARD, Emmanuel. "Transnational Law: A Legal System or a Method of Decision Making?". Arbitration Internationl. 2001, vol 17, $\mathrm{n}^{\circ}$ 1, p. 61.

GAILLARD, Emmanuel. "Trente ans de Lx mercatoria puor une application sélective de la méthode des príncipes généraux du droit". Journal du Droit international. 1995, no 1, 1995, p. 5-30.

GAILLARD, Emmanuel. Teoría jurídica del arbitraje internacional. Asunción. La ley/CEDEP, 2010.

GALGANO, Francesco. "Lex mercatoria e legittimazione". Sociologia del Diritto. 1995, n² 2-3, p. 201-202

GLITZ, Frederico Eduardo Zenedin. "Transferência do risco contratual e incoterms: breve análise de sua aplicação pela jurisprudência brasileira”. In CORTIANO JUNIOR, Eroulths; et al. (eds.). Apontamentos críticos para o Direito civil brasileiro contemporâneo II - Anais do Projeto de Pesquisa Virada de Copérnico. Curitiba: Juruá, 2009, p. 111-139.

GOLDMAN, Berthold. "As fronteiras do Direito e Lex Mercatoria". Archives de Philosofie du Droit. 1964, vol 9, nº 9, p. 177-192.

GOLDMAN, Berthold. "Frontières du Droit et Lex mercatoria". Archives de Philosophie du Droit. 1964, vol 9, n 9, p. 177-192.

GOLDMAN, Berthold. "Nouvelles Réflexions sur la Lex Mercatoria". Festschrift Pierre Lalive. Franckfurt: sn., 1993

GOLDSTAJN, Aleksandar. "Usages of trade and other autonomous rules of international trade according to the UN (1980). Sales Convention". In: SARCEVIC, Petar; VOLKEN, Paul. (eds.). International Sale of Goods: Dubrovnik Lectures. New York: Oceana, 1986, p. 55-110. 
GONDRA ROMERO, Jose Maria. “La moderna 'lex mercatoria' y la unificación del derecho del comercio internacional". Revista de Derecho Mercantil. 1973, n 127, p. 7-38.

GOODE, Roy. "Regla, práctica y pragmatismo en el derecho comercial transnacional". In: BW, Jürgen; FERNÁNDEZ ARROYO, Diego P.; MORENO RODRIGUEZ, José A. (eds.). Cómo se codifica hoy el derecho comercial internacional. Asunción: La Ley/CEDEP, 2010, p. 75-106.

GOODE, Roy. "Usage and its reception in transnational commercial Law". In: International and Comparative Law Quarterly. 1997, vol 46.

GOODE, Roy; KRONKE, Herbert; MCKENDRICK, Ewan. Transnational commercial law: texts cases and materials. Oxford: Oxford press, 2007.

GRANDE, Silvana. "La Lex Mercatoria en los laudos de la Cámara de Comercio Internacional”. Díkaion. 2008, vol 22, n 17, p. 240-241.

GREBLER, Eduardo. "O contrato internacional no Direito de empresa”. Revista de Direito Mercantil. 1992, n 85, p. 27.

GROSSI, Paolo. De la codificación a la globalización del derecho. Pamplona: Aranzadi, 2010.

GROSSI, Paolo. História da propriedade e outros ensaios. Rio de Janeiro: Renovar, 2006.

HOWARTH, Richard J. "Lex mercatoria: can general principles of law govern international commercial contracts?". Canterbury Law Review. 2004, vol 10, p. 36-76.

JAQUET, Jean-Michel; DELEBECQUE, Philippe. Droit du commerce international. París: Dalloz, 1997

JOHNS, Fleur. "Performing party autonomy". Law and contemporary problems. 2008, vol 71, p. 243-271

KASSIS, Antoine. Théorie générale des usages du commerce: droit compare, contrats et arbitrage internationaux, lex mercatoria. Paris: LGDJ, 1984.

LAGARDE, Paul. "Approche critique de la Lex mercatoria". In FOUCHARD, Philippe et al. (eds.). Le droit des relations économiques internationals: etudes offertes a Berthold Goldman. París. Librairies Techniques, 1982

LEDUC, Antoine. "L'emergence d'une nouvelle lex mercatoria a l'enseigne 
des príncipes d'UNIDROIT relatifs aux contracts du commerce international: these et antithese". Revue Juridique Thémis. 2001, vol 35, p. $429-451$.

LÓPEZ RODRÍGUEZ, Ana M. Lex mercatoria and harmonization of contract law in the EU. Copenhagen: DJOF Publishing, 2003.

LOWENFELD, Andreas F. "Lex mercatoria" [online]. An Arbitrator's View, arb. Internl., 1990, p. 150. Disponible en: zwww.trans-lex.org/ output.php?docid $=126000>$

MADRUGA FILHO, Antenor Pereira. “A CIDIP-V e o Direito aplicável aos contratos internacionais". Revista de Direito de Empresa. 1996, n 1 , p. $75-124$.

MAEKELT, Tatiana B. de. "La flexibilización del contrato internacional en La Convención Interamericana sobre Derecho aplicable a los Contratos Internacionales". In: CASELLA, Paulo Borba (ed.). Dimensão Internacional do Direito: estudos em homenagem a G. E. do Nascimento e Silva. São Paulo: LTr, 2000, p. 269-276.

MANIRUZZAMAN, Abul F. M. "The lex mercatoria and international contracts: a challenge for international commercial arbitration". American Uniform and International Law Review. 1999, vol 14, p. 732734.

MICHAELS, Ralf. “The true Lex mercatoria: Law Beyond State”. Indiana Journal of Global Legal Studie. 2007, vol 14, n² 2, p. 467-468.

MOLINEAUX, Charles. "Moving Toward a Lex Mercatoria - A lex Constructionis". J. Int'l Arb. 1997, vol 14, no 1, p. 55-56.

MORENO RODRÍGUES, José Antonio. "La nueva lex mercatoria: ¿un fantasma creado por profesores de la Sorbona? Foro de Derecho Mercantil”. Revista Internacional. 2003, nº 1, p. 95-124.

MORENO RODRIGUEZ, José Antonio. Contratación y arbitraje: contribuciones recientes. Asunción: CEDEP, 2010.

MOSSET ITURRASPE, Jorge; PIEDECASAS, Miguel A. Contratos: aspectos generales. Buenos Aires: Rubinzal-Culzoni, 2005.

MUSTILL, Michael. The new Lex Mercatoria: The First Twenty-five Years, Arbitration International. 1998, vol 4, p. 116-117.

NOTTAGE, Luke. "Changing Contract Lenses: unexpected supervening events in English, New Zeland, U. S. and Japanese, and International Sales Law and Practice". Indiana Journal of Global Legal Studies. 2007, 
vol 14, n 2, p. 385-418.

NUSDEO, Fábio. Fundamentos para uma codificação do Direito econômico. São Paulo: RT, 1995.

OPPETIT, Bruno. Droit et modernité. Paris: Puf, 1998.

OSMAN, Filali. Les príncipes généraux de la lex mercatoria: contribution a l'etude d'un ordre juridique anational. París: LGDJ, 1992.

PARK, William W. "Control mechanism in the development of a modern lex mercatoria". CARBONNEAU, Thomas (eds.). Lex mercatoria and arbitration: a discussion of the new law merchant. New York: Transnational Juris, 1990.

PAULSSON, Jan. "La lex Mercatoria dans l' Arbitrage C.C.I". Revue d' Arbitrage. 1990, p. 55-100.

PELLET, Alain. “La lex mercatoria, 'Tiers Ordre Juridique'?”. In: LEBEN, Charles, LOQUIN, Eric; SALEM, Mahmoud (eds.). Remarques Ingenues d'un Internationaliste de Droit Public. Souveraineté étatique et marchés internationaux a la fin du 20éme siele - Mélanges en l'honneur de Philippe Kahn. París: Litec, 2000, p. 53-74.

PINHEIRO, Luís de Lima. "O Direito autônomo do comércio internacional em transição: a adolescência de uma nova Lex mercatoria". In: Estudos de Direito Civil, Direito Comercial e Direito Comercial Internacional. Coimbra: Almedina, 2006.

PINHEIRO, Luís de Lima. Direito comercial internacional. Coimbra: Almedina, 2005.

PINHEIRO, Luis de Lima. Direito Internacional Privado: introdução e direito de conflitos. Parte geral. 2 ed. Coimbra: Almedina, 2008.

PROCACCIA, Uriel. “The case Against Lex Mercatoria”. In: ZIEGEL, Jacob S. (ed.). New Developments in International Commercial and Consumer Law: proceedings of the 8th Biennial Conference of the International Academy of Commercial and Consumer Law. Oxford: Hart, 1998.

RECHSTEINER, Beat Walter. Direito internacional privado: teoria $e$ prática. $7^{a}$ ed. São Paulo: Saraiva, 2004

ROSEN, Mark D. “The empirical and theoretical underpinnings of the Law Merchant: do codification and private international Law leave room for a new Law Merchant?". Chicago journal of International Law. 2004, vol 5, no 1, p. 86-87. 
SARACHO CORNET, Teresita; DREYZIN DE KLOR, Adriana. Derecho internacional privado: una visión actualizada de las fuentes. Córdoba: Advocatus, 2003.

SBORDONE, Francesco. Contratti internazionali e lex mercatoria. Napoli: Edizioni Scientifiche Italiane, 2008.

SCHMITTHOFF, Clive M. "Les nouvelles sources du Droit commercial international. UNESCO”. Revue Internationale des sciences socials. 1963, vol 15, n' 2, p. 267-273.

SCHULTZ, Thomas. "The concept of law in transnational arbitral legal orders and some of its consequences". Journal of International Dispute Settlement. 2011, vol 2, no 1, p. 59-85.

SHAPIRO, Martin; SWEET, Alec Stone. On law, politics \& judicialization. Oxford: Oxford press, 2002, p. 322.

SOARES, Guido Fernando Silva Soares. "El orden público en los contratos internacionales". Revista de Direito Mercantil, Industrial, Económico e Financeiro. 1984, nº, p. 122-129.

VIRALLY, Michel. El devenir del Derecho internacional: ensayos escritos al correr de los años. México: Fondo de Cultura Económica, [199?].

WALD, Arnoldo. "A introdução da Lex mercatoria no Brasil e a criação de uma nova dogmática”. Revista de Direito Mercantil, Industrial, econômico e Financeiro. 1995, n 100, p. 20-23. 